Calibration is made through different series resistors which correspond to impedances of preparations up to 10 megohms.

It will be noticed that the input is asymmetrical. This allows the input terminal connected to plate supply minus to be used as a screen between a source of interfering potentials and the grid. This is particularly suitable for recordings from nerves. An analysis of the discriminative properties of the input stage when used in this way shows the importance of keeping the stray capacitance from input grid to ground as small as possible. This suggests that the connection between electrode and input grid should be screened and the screening connected to the cathode of 955 .

The graph in Fig. 5 gives the discrimination at fre- quencies from 50 to 16,000 cycles when a resistance $R$ of different values up to 10 megohms is connected to the input stage and the interfering signal is applied between plate supply minus and ground. The upper curve $(R=0)$ corresponds to the generally given definition of the discrimination factor. At dc the discrimination, of course, reaches a practically infinite value. It can be mentioned that in most cases the grounding of the preparation can be omitted without troublesome line frequency pick-up.

The input unit has also been used for electromyography, electrocardiography, and encephalography. When the high frequency response is reduced to that needed in E.E.G. recording, the noise amounts only to a few microvolts.

\title{
Remote Opening and Sealing of Metal Tubes
}

\author{
L. T. Loh, H. W. NeILl, M. H. Nichols, and E. A. Wenzel \\ Department of Aeronautical Engineering, University of Michigan, Ann Arbor, Michigan
}

(Received May 29, 1951)

\begin{abstract}
"One-shot" methods of opening and sealing metal tubes are described. These methods were developed for taking high altitude atmospheric samples in metal bottles carried aloft by rockets and are performed by pyrotechnic means. The sealing is done by cold welding.
\end{abstract}

\section{INTRODUCTION}

A S part of a program of high altitude meteorological research sponsored by the Meteorological Branch of the U. S. Army Signal Corps, ${ }^{*}$ atmospheric samples have been taken as high as $70 \mathrm{~km}$ by means of rockets. These samples have been subsequently analyzed at the University of Durham by Professor Paneth and coworkers ${ }^{1}$ and at the University of Michigan. ${ }^{2}$ A complete description of the sampling procedure and analytical results at the University of Michigan will be published elsewhere. It appears to the authors that the techniques used for opening the evacuated sample bottles and subsequently sealing them after the sample is admitted are sufficiently useful in other fields to justify a detailed description of these techniques in this journal.

\section{OPENING OF THE EVACUATED SAMPLE BOTTLES}

The opening of the evacuated sample bottles has been accomplished in three ways: by a knife soldered to a sylphon bellows which is extended by a charge of gun cotton, by a motor-driven knife, and by a charge of black powder which drives a piston. The piston is

\footnotetext{
* Contract No. W-36-039 sc 32307.

1 Chackett, Paneth, and Wilson, J. Atmos. and Terres. Phys. 1 49 (1950); also Chackett, Paneth, Reasbeck, and Wiborg, Nature 168, 358 (1951).

2 Hagelbarger, Loh, Neill, Nichols, and Wenzel, Phys. Rev. 82 107 (1951); also Jones, Loh, Neill, Nichols, and Wenzel, Phys. Rev. 84, 846 (1951).
}

arranged so as to tear off the end of the intake tube upon extension. The first method is the simplest, is compact, and does not evolve gas if properly sealed. It is practical if not too large an opening is required and if the presence of the extended bellows is not objectionable. Later developments made possible the use of larger intake tubes and made the presence of the bellows in front of the opening objectionable so the motor-driven knife was then used. This consisted of a pivoted knife driven by a motor assembly which cut off a one-inch diameter intake tube at a thin section. Although this method was used with some success on two flights, it proved impractical because of electrical power requirements, etc., so the third method was developed. Since the first method may be practical in many applications, it, as well as the third method, will be described.

\section{II.1 Pyrotechnic Bellows Opener}

The apparatus consists of a sylphon bellows $A$ onto the closed end of which a steel knife $B$ is hard soldered as indicated in Fig. 1. A charge of gun cotton $C$ is used to extend the bellows, thereby driving the knife through the thin copper diaphragm $D$ which is hard soldered across the end of the tube $E$ which is to be opened. The following data apply to this opener:

Squib wire-nichrome 0.0025 -in. diameter.

Squib capsule-short end of No. 00 gelatin capsule. The capsule is fastened to the squib holder $F$ with commercial Duco cement. 




FIG. 1. Schematic of pyrotechnic bellows opener.

Sylphon Bellows-Fulton Sylphon Company, $\frac{3}{4}$-in. o.d. $5 R B$ (five convolutions) $1 \frac{1}{2}$-in. extended, brass, wall thickness 0.005 -in.

Gun cotton-30 mg gun cotton DuPont type $n / c 13.15$ percent nitrogen, blend 2233 with 33 percent water (in contact with squib wire). The gun cotton is baked at $175^{\circ} \mathrm{F}$ for about four hours to remove water before putting it in the capsule.

Copper diaphragm $D-0.003$-in. thick hard soldered to end of tube $E$.

Tube $E$-brass $\frac{5}{8}$-in. o.d., $\frac{3}{32}$-in. wall.

\section{II.2 Pyrotechnic Piston Opener}

This type of opener is shown schematically in Fig. 2. It consists of a piston $A$ behind which is the black powder $B$. When the black powder is ignited by the squib wire $C$, it drives the piston $A$ against the collar $D$ which tears off the closed end of the one-inch diameter intake tube $E$ at the thin section $F$. The collar and tube end fly off at an angle. The tube $G$ is used for evacuating the sample bottle and is sealed off by cold welding. The following are pertinent details:

Squib wire-nichrome 0.0025-in. diameter.

Squib capsule-long end of No. 00 gelatin capsule.

Black powder -0.5 grams.

Tube $E$ material-copper, see Sec. III.1.

Thin Section $F-A$ brass cap is hard soldered to the tube $E$.

The cap is cut away at $F$ to a thickness of 0.005 in. at the bottom of the "V" groove.

In order to prevent escape of gas from the powder into the space above the mounting plate shown in Fig. 2, an "O" ring shown in Fig. 2 was used. Vent holes are shown in the shoulder on which the lower end of the piston rests before firing. These vents let the gas, which blows by the piston, escape into the space below the plate. The piston is greased to reduce blow-by.

\section{SEALING OF THE SAMPLE BOTTLES AFTER ADMISSION OF THE SAMPLE}

Whether recovered from the wreckage of the rocket or from a parachute drop, the seal must withstand considerable shock and in some cases heat. In several instances the sample bottles were flattened to a fraction of their original volume. The sealing apparatus must withstand the launching shock, etc. Also, it is sometimes difficult to locate the sampling apparatus after the flight, and several weeks or months may elapse before the sample bottles are recovered.

The method of sealing the sample bottles first tried consisted of a spring-driven mechanism which, when released, squeezed shut a thin-walled copper tube of $\frac{1}{4}$-in. diameter. The inside of this tube had been previously coated with solder. The copper tube was then heated to above the melting point of solder by the passage of electric current from a standard filament transformer with a heavy one-turn secondary. The primary of the transformer was connected to a 500 -watt 400 -cycle battery-driven rotary converter. This method was successful in the laboratory and was used on an early flight. However, no samples were taken by this technique, owing to rocket failure. Since a large battery and converter were required, the method was abandoned in favor of pyrotechnic methods.

The first pyrotechnic method was developed and produced for the atmospheric sampling by the Piccatiny Arsenal. A hammer driven by a black powder charge squeezed a slightly flattened copper tubing shut against a fiber anvil. Firing of the black powder also ignited a fuse (quick match) which in turn ignited a charge of nongaseous fuse powder in the hammer head. Sufficient heat was evolved to melt solder on the inside of the tube, thus effecting a seal. This method was successful and was used on numerous flights, but it always gave

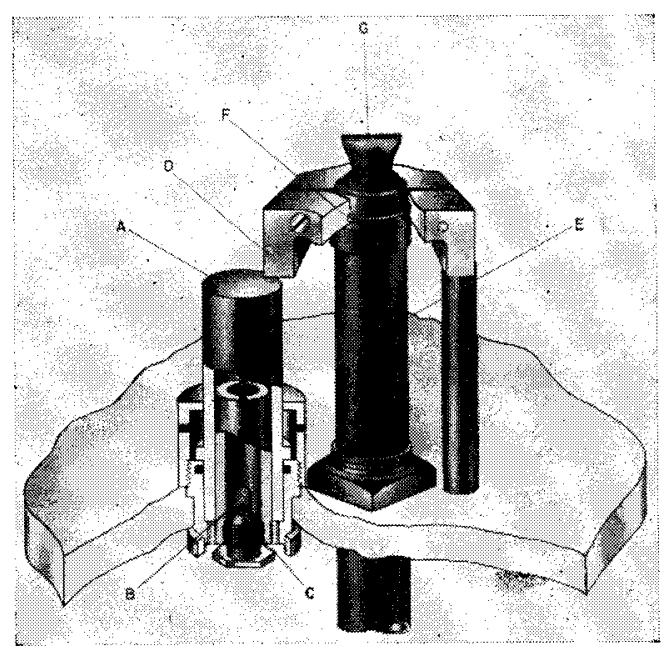

FIG. 2. Schematic of pyrotechnic piston opener. Part of the yoke $D$ is shown cut away to aid in visualizing its construction. The piston $A$ travels about $\frac{1}{4}$ in. before it hits the yoke $D$ in order to givejit_a"sharp.blow. 
off a certain amount of gas, owing to the heating, and at the same time it appeared that some of the oxygen in the sample reacted with the hot copper. ${ }^{1}$ Also, the crosssectional area of the tube which could be conveniently soldered by this means was limited. For these reasons a cold welding method was developed which is not subject to these objections.

\section{III.1 Cold Weld Sealer}

Certain metals such as copper, silver, and platinum can be welded together to give a vacuum tight seal by the application of sufficient pressure. ${ }^{3}$ Some advantages of this type of welding are instantaneous sealing and the lack of heat except that developed from the working of the metal, which is quickly conducted away. Because of the lack of heat, gas is not released during the sealing process. Figure 3 is a schematic of the sealer used by the writers. This sealer functions as follows: A charge of black power $A$ is ignited by the squib wire shown. The pressure generated drives the cylinder $B$ against the jaw $C$ which squeezes the copper tube $D$ between $C$ and $E$. The force is great enough to pinch off tube $D$ and to cold weld the edges of the pinch together. It is estimated that the charge of black powder used develops somewhat over 10,000 pounds thrust on the jaws. When properly made, the seals are vacuum tight as indicated by a helium leak detector and by aging of the seals on an evacuated bottle in which a Pirani gage is mounted. The apparatus sketched in Fig. 3 was made of high tensile steel to save weight. Some pertinent details are:*

${ }^{3}$ A. B. Sowter, Welding J. 28, 149 (1949); W. Dubilier, Welding J. 29, 1077 (1950).

* Footnote added in proof.-Further experience has indicated that cleaning by brushing with a wire brush is more effective in producing a strong weld than is the chemical cleaning (see reference 3). As compared to chemical cleaning, brushing appears to reduce the pressure required for successful welding. Our current procedure is to brush with a steel-wire wheel after the chemical cleaning outlined above. The sample bottle is then evacuated immediately to minimize subsequent surface corrosion. Also, it should be mentioned that the chemical analyses (see reference 1) have indicated substantial decrease in oxygen content in the sample even with the cold weld technique.

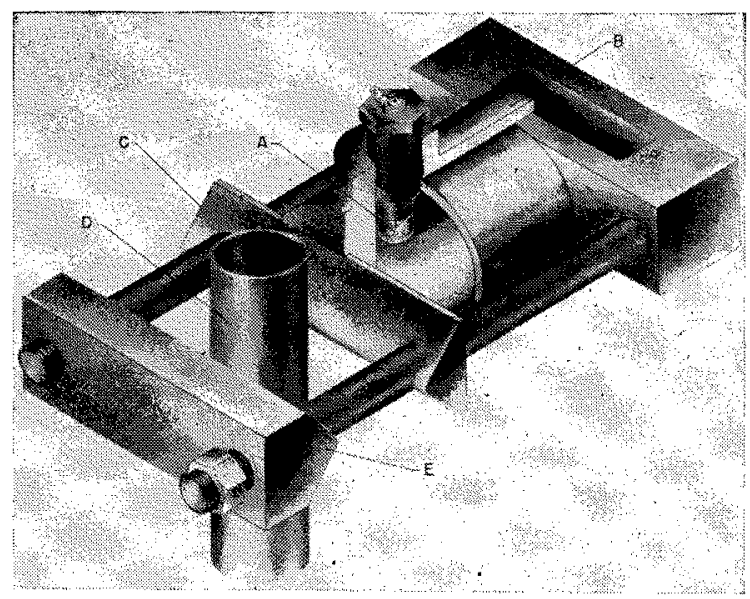

FIG. 3. Schematic of cold weld sealer.

Powder-5.5 grams (Piccatiny Arsenal grade A5) fine grain black powder (part of this charge is used to fill the squib capsule, and the balance is poured into the firing chamber).

Squib wire-nichrome 0.0025 -in. diameter.

Squib capsule-short end of No. 00 gelatin capsule filled with black powder.

Copper tubing-Revere type $L$ copper water pipe 1 -in. i.d. by $1 \frac{1}{8}$-in. o.d. Oxide scale is brushed off and cleaned in dilute solution of $\mathrm{HCl}$ for approximately five minutes. It is then rinsed with tap water and dipped for several minutes in copper cleaner (13 oz chromic acid dissolved in one gallon distilled water to which $7 \mathrm{cc}$ of concentrated sulphuric acid is added). The tube is then thoroughty rinsed in distilled water. It is possible that oxygen-free type of copper tubing might work better.

Early failures of sealing have disclosed the fact that during the sealing both ends of the copper tubing should be held rigidly. If one end was free to move during the sealing, the tube had a tendency to break prematurely at the site of the sealing and resulted in a leaking seal. It should be mentioned that in the first flight of this type of sealer, the squib wire failed to ignite the black powder because the air had leaked out of the firing chamber of the sealer. The leaking was prevented by greasing the piston and the plug that holds the powder charge, and in subsequent flights the sealers operated satisfactorily. 